\title{
Communicative Teacher Talk in the English Classroom
}

\author{
Xuelian Lei \\ The School of Foreign Languages \\ Hangzhou Normal University \\ Hangzhou 310036, China \\ Tel: 86-571-2888-7744 E-mail: thundersnow@126.com
}

\begin{abstract}
Communicative approach has become popular in ELT in recent years. Good teacher talk lays focus on how effectively it could promote genuine communication in the classroom. In this essay, communicative teacher talk is studied, and its features are explored based on authentic classroom transcripts, and a summary of the existing problems is provided.
\end{abstract}

Keywords: Communicative, Teacher talk, Features, Problems

\section{Introduction}

"Creating a real life situation in English language teaching" has become a fashion in recent years. To be exact, that is the communicative approach. It provides a way to solve the problem that has existed in ELT for many years. The problem is that the students, after receiving several years of English teaching, are still unable to use the language, to communicate with the language. The communicative app roaches have suggested that one goal of English language teaching should be to promote genuine and natural classroom communication.

Until comparatively recently, teacher talk in the EFL classroom was considered to be a problematic area for language teachers. For one time, it was thought that "good" teacher talk meant "little" teacher talk, since

too much teacher talk deprived students of opportunities to speak. However, it should be the "quality" rather than the "quantity" that counts. "Good teacher talk" should be judged by how effectively it was able to facilitate learning and promote communicative interaction in the classroom. The teacher talk that promotes the facilitation of classroom interaction is therefore called communicative. The teacher talk includes, for example, the kind of questions they ask, the speech, modifications they make when talking to learners, and the way they react to students errors.

\section{Features of Communicative Teacher Talk}

If we pursue real communication in the classroom, there are a number of characteristics of teacher talk, which we identify as being communicative.

\subsection{Referential Questions}

Referential questions are genuine questions for which the teacher does not know the answers and therefore has a genuine communicative purpose. This is in contrast to displaying their understanding of knowledge. There is plenty of evidence to suggest that in the nowadays classrooms, the vast majority of questions teachers ask are display questions without communicative purposes. While in real life, most questions are referential. There is a marked difference between typical classroom talk and non classroom talk in this respect.

\subsection{Content Feedback}

Feedback on content involves responding to the content of what learners are saying, rather than commenting solely on the form. After all, if no attention is paid to the meanings the learner is expressing, there is no point in asking referential questions.

\subsection{Avoidance of the IRF Sequence}

IRF sequence goes like this: the teacher asks a question and the students give the answer; then the teacher provides his/her comments on the answer as feedback. This is the typical sequence of the classroom talk. The structure of spoken discourse outside the classroom is usually more complex and flexible than this. When we taught College English Book 3 for the first time, our teaching method experienced a painful change. In this reform process, we could say that the three features above found good expression in the teaching. Following are the transcripts to illustrate the change.

Transcript A:

T: Today, we are going to study Lesson Six “The Human Touch”. First, I will give you several minutes to go through 
the text, and after that, I have several questions for you ... ok now?

S: Yes.

$\mathrm{T}$ : Who is $\mathrm{O}$ ' Henry?

S1: Of course, a writer.

T: Good. Who knows more about the writer?

S2: A famous writer.

$\mathrm{T}$ : Right. Who knows why he is known as a famous writer?

S3: Sorry.

T: Don't worry. Think it over.

S4: He is a famous short story author.

T: Fine. What else do you know about him?

S4: Sorry.

T: Ok. Now, let's study the new words in this text. The first one is "victim". "Victim" means person, animal, etc. suffering death, injury or loss. Can you make a sentence with "victim"?

S5: Sorry, I can't do it.

T: Ok.

We view the class as a failure for it is a typical uncommunicative fragment of classroom talk. The class was thought of as uncommunicative simply because it fails to exhibit features of communication which is in contexts outside the classroom. Our questions are all display questions, since the purpose is to know if the students understand the text and the words, and

to enable them to display their knowledge. Our feedback to the students' responses is simply acknowledgements to mean that the answer is acceptable. The talk obviously follows the IRF sequence. That is, the teacher asks a question, then the student responds, and the teacher asks another. Soon, we find that the students easily get bored, and gradually they become more and more uncooperative. They begin to talk to each other, flip through the book or even fall asleep in the class. We know that it is not the students that are to blame, but the teaching, the method. Then we experimented with a new approach to classroom questioning and initiation as is rep resented by Transcript B.

Transcript B:

T: Hi, Sunny, do you like reading novels?

S1: Yes, of course. I read a lot in my spare time.

T: Ha, the same with me. Then, which novel do you like best?

S1: Oh, "Gone with the Wind" is my favorite book, and I have ever read "A farewell to Arms". I could say it is perfect.

T: I have read it for several times, to tell you the truth. And I find the "Gone with the Wind" is very attractive indeed. Now, here comes the question, have you read the "The Gif t of the Magi"?

S1: Oh, of course. The story is very impressive.

T: But I wonder who wrote it?

S2: O' Henry.

T: Great. Who can tell me what novels he had written besides this one?

S3: The Cop and the Anthem.

T: Good, Lesson Six tells us a story written by the same author. Now let us look at what happened to the girl named Johnsy and why Sue called the painted leaf Behrman's masterpiece. Read the text and tell me the answers.

(Several minutes later)

S4: Sue's roommate Johnsy caught pneumonia, and she decided that she would die when the last ivy leaf fell.

T: Good. . . Now let us relax a little. Jason, do you like drawing?

S5: Yes, I began to draw when I was a little boy.

T: Oh. How do you tell the genuine from the fake ones?

S5: Ha. . . I. . . I. . . perhaps, I think it is not an easy job for me if the fake is too much like the real one. 
T: Now, let's come to the second question.

S6: Because it was so perfect that the girls both mistook it for the real thing.

We chose Transcript B not because we think it is flawless but because we feel it is an example of genuine interaction between ourselves and the students, and in particular because WE consider it a breakthrough with the class. In the past, students were reluctant in initiating discussions, asking or answering questions during the class probably because the questions were not communicative and they were not sure about their language ability. During the class, insecurities were somewhat forgotten as the students forgot about the classroom context and enthusiastically attempted to answer the questions they are interested in. More real communication was seen when they began to differ in their opinions.

In the class talk, most of the questions were referential with the communicative purpose and the teacher's response was on the content rather than on the form.

\subsection{Student initiated Talk}

Acquisition is facilitated by the negotiation of meaning in interaction. Teachers should try to negotiate meaning with students, through asking for clarification and repetition, and giving students opportunities to interrupt the teachers. Although there is usually much less learner initiated than teacher initiated content in classroom, it is usually from the former that learners claim to have learned the most.

Some teachers give the students absolutely no space meaningful negotiations. They are complete authority ignoring the students' contribution, in fear that the teaching objectives will not be met. There is no interaction between students. They only allow time for this, if any, in the free practice towards the end of the lesson, and thus the lesson not at all flowing along the interactive path.

Usually the teacher does all the talking, and then the students are left on their own. Then, how should the teacher react if the students ask questions? Does the teacher simply provide the answer or guide the students to solve the problem by themselves? It is easy, in any problem solving situation, for the wrong person to become responsible for solving the learning problems. Obviously, providing the answers promptly deprives the learner of opportunities to learn how to solve problems and snuff the communication between the teacher and the learner. So, the key question is often not how to solve the problem itself, but how to make sure that the right person solves it. The teacher should always ensure that she herself and the learners play their proper roles in problem solving processes. The following two transcripts show the difference between teacher initiated (Transcript C) and learner initiated (Transcript D) talk.

Transcript C

S: Excuse me, I don't understand this word.

T: Ok. Let me see if I can help. Ah, yes, delegate'. Well, for example, if I ask you to do the things that I normally do, like cleaning the blackboard or giving out your exercise books, etc. I am delegating. ' Is that clear for you now?

S: Yes. I think so.

T: OK.

Transcript D

S: Excuse me, I don't understand this word.

$\mathrm{T}$ : Hm, delegate. So the meaning has to be found. Do you remember seeing it before anywhere?

$\mathrm{S}$ : Ah, yes, now I remember. I think it was in the last unit. (flipping through the pages) Here it is. It means to get someone else to do something that you normally do yourself.

$\mathrm{T}$ : Yes, can you think of an example?

S: Yes, like when you ask one of us to clean the blackboard, or give out the books. Then you delegate those jobs to us, right?

\section{T: Good.}

\subsection{The Teaching of Value Rather Than Significance}

It is necessary to draw a distinction between two different kinds of meaning, one of which refers to the explicit meanings that language items have as elements of the language system, and the other is that part of meaning that the language items have when they are actually put to use in acts of communication. The first kind of meaning is called significance, and the second kind is value. During the class, it is the value rather than significance that should be taught. What the students are concerned about is the value, because they can find the significance in text books and dictionaries easily.

Let us suppose that we wish to teach the present continuous tense. The typical way of significance teaching goes like this, which can still be seen in many of our current teaching practice. The teacher opens the door, saying "I am opening 
the door", and getting a number of students to do the same while he says "he is opening the door; they are opening the door", and so on. Then the teacher asks some students to write on the blackboard while commenting "I am writing on the blackboard; he is writing on the blackboard; they are writing on the blackboard". The teacher tries to show what the $\mathrm{p}$ resent continuous tense signifies and how students can use the rule to develop sentences. But these sentences have little communicative significance in real life situations?

\section{Problems in the Communicative Teacher Talk}

We have discussed above that the features of genuine communication are the use of referential questions rather than display ones. The use of referential questions over display questions is likely to stimulate a greater quantity of classroom interaction. Furthermore, the turn of the conversation should not be the fixed pattern: teacher asks student answers teacher responds. Yet, research has found that display questions and the IRF sequence always appears in the parent child conversation. The structure resembles that which takes place in the ELT classroom.

(Mother and Jack look at pictures)

M: What are those?

J: Shells.

M: Shells, yes. You've got some shells, haven't you? What's that?

\section{J: Houses.}

Parent-child interactions resemble those in the classroom in that the goal of both discourses is learning or education. The display questions and the IRF sequence are interaction features well suited to this goal. In the class, the teacher acts as the transmitter of knowledge and a valuable source of input for the learner. Sometimes it seems that the display questions are necessary for the teacher to use to test the learners' knowledge. The business of learning is accomplished through these features. As to the teaching of value rather than significance, the circumstances of classroom are restricted, how could all the values of the meanings are taught in the classroom, since there is no simple equation between linguistic forms and communicative functions. Also, the teachers live and work with grammatical and lexical syllabuses, and the textbooks have little relation to the world the learner lives in.

The contradiction is that: how can teaching be made more truly communicative by breaking the constraints within which most teachers work?

The free conversation outside the classroom has many features of its own. In order to carry on a free talk, the participants of the conversation must be unrestricted and all of them share the responsibility for managing and monitoring the progress of the discourse.

The ELT lesson could become identical to real2life conversations, provided that the learners regard the teacher as a fellow2conversationalist of equal status rather than as a teacher. The teacher should not direct the conversation. However, the stated purpose of ELT lesson is to teach English to foreigners. As soon as the teacher instructs the learner to have conversation in English, the interaction could not be genuine conversations as defined here. To replicate conversation, the lesson would cease to be a lesson and become a conversation, which does not have any underlying pedagogical purpose. It is therefore very hard for teachers to produce genuine and natural communication in the classroom.

So, the problem is whether it is possible for teachers to replicate genuine or natural communication in the classroom.

To answer this question, one thing must be made clear is whether the classroom can accommodate all kinds of communications in ELT. The criterion for assessing the communicativeness of classroom discourse is taken from what is thought to constitute communicative behavior in the world outside the classroom. The criteria might be generally true of informal gatherings of group $s$ of friends but certainly not of more formal gatherings. Communication at such events tends to follow a very different pattern, determined by their own rules and conventions.

Similarly, the classroom, typically a large, formal gathering which comes together for pedagogical rather than social reasons, will also have its own rules and conventions of communication, understood by all those present. These patterns are likely to be very different from the norms of turning taking and communicative interaction, which operate in small, informal, social gatherings outside. That is not to deny the importance of analyses of the properties of spoken discourse found in contexts outside the classroom. They shed light on what the wider teaching goal should be, and suggest the ways that the communication in classroom should be moderated. But, that is very different from suggesting that the classroom only needs to replicate communicative behavior outside the classroom in order that the classroom context, genuine communication can be redefined, and better solutions can be found.

\section{References}

Brumfit, C. J. \& Johnson, K. (1983).The Communicative Approach to Language Teaching. Oxford: Oxford University Press. 
Cullen, R. (1998). Teacher Talk and the Classroom Context. ELT Journal, (52 /1): 1792186.

Johnson, K. (1983). Communicative Syllabus Design and Methodology. Oxford: Pergamon Press.

Lynch, T. Nudge. (1997). Nudge: Teacher Interventions in Task Based Teacher Talk. ELT journal, (51/4): 3172325.

Malamah Thomas. (1987). A Classroom Interaction. Oxford: Oxford University Press.

Richards, C. J. (1985). The Context of Language Teaching. Cambridge: Cambridge University Press.

Seed house, P. (1997). Classroom Interaction: Possibilities and Impossibilities. ELT Journal, (50/4): 16224. 